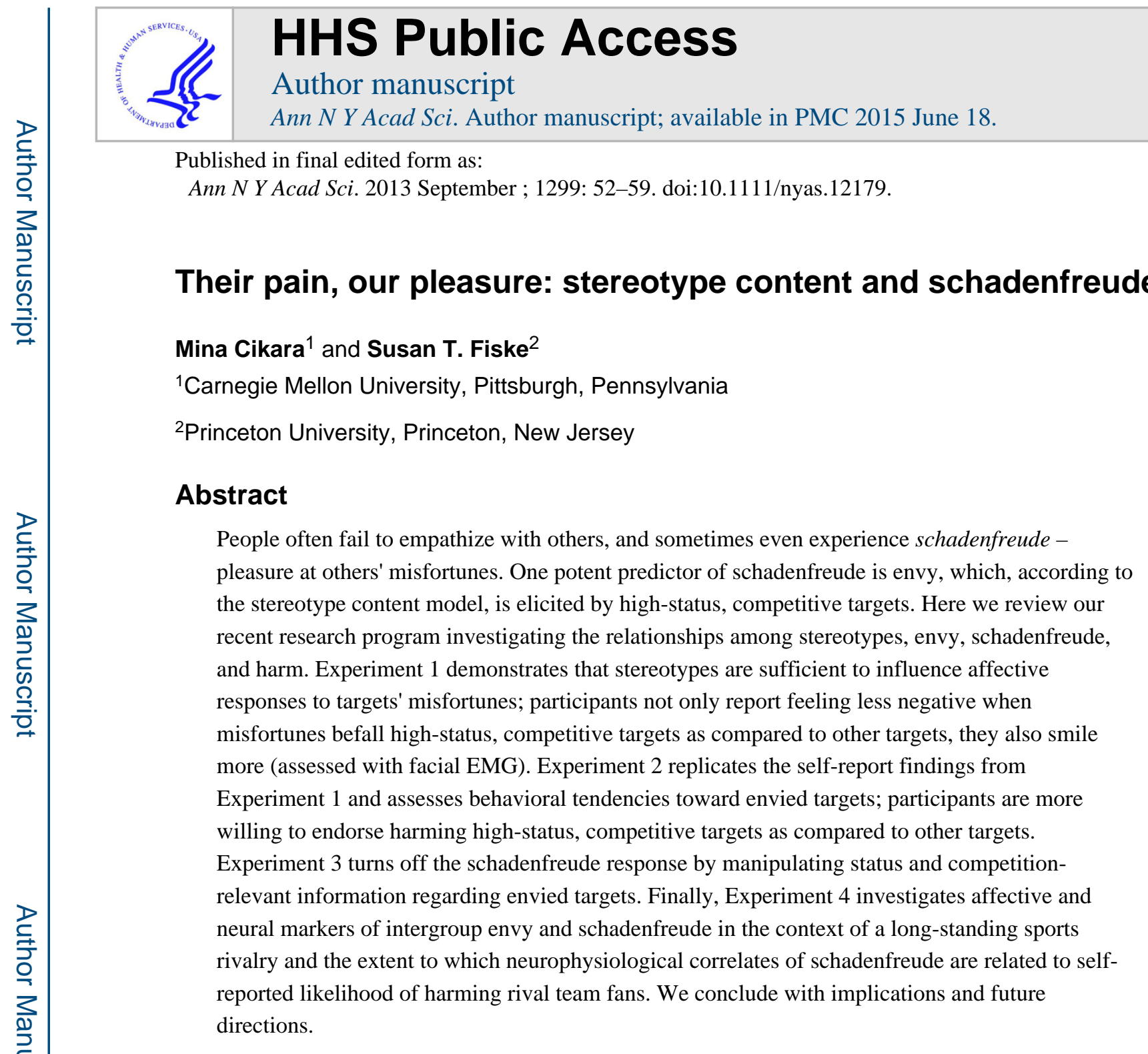

Keywords

envy; schadenfreude; stereotypes; prejudice; harm

The capacity for empathy is one of the most important faculties that humans possess; it is a powerful motivator of pro-social behavior and cooperation, cornerstones of humanity's most cherished interpretations of sociality and responsibility (Batson, 2009; Keltner, 2009;

Tomasello, 2009). Empathy is also, for better or for worse, bounded: people do not empathize with everyone all the time. Specifically, people often feel less empathy for outgroup members-individuals who belong to groups of which the observer is not a part (Batson \& Ahmad, 2009; Cosmides, Tooby and Kurzban, 2003; Davis, 1994; Hornstein, 1978). This intergroup empathy bias (Cikara, Bruneau \& Saxe, 2011) matters because failures of empathy in response to the suffering of out-group members predict an absence of

Corresponding Author: Susan T. Fiske, Psychology and Public Affairs, Princeton University, Princeton, NJ 08540, sfiske@ princeton.edu. 
pro-social responding (Johnson, Simmons, Jordan, et al., 2002). And lack of empathy for out-groups can place them beyond the bounds of apparent ethical relevance.

More recent research has started to explore another manifestation of intergroup empathy bias: counter-empathic responding. Instead of empathy or apathy, people sometimes feel pleasure - schadenfreude - in response to out-group members' pain. These counter-empathic responses may at best allow indifference to others' suffering, and at worst facilitate harm against them. In light of this, we ask: which groups are most likely to be targets of schadenfreude? Furthermore, how much exposure to or experience with an out-group do people need to experience schadenfreude in response to out-group members' misfortunes? Do the out-group members have to act in harmful ways, or are mere stereotypes sufficient?

Here we review our research examining the antecedents and consequences of intergroup schadenfreude. First, we briefly review predictors of schadenfreude, with an emphasis on envy. Next, we discuss how these emotions manifest at the group level: which groups are the most likely to elicit envy and schadenfreude as well as potential consequences of these emotions for these groups. We summarize four experiments specifically examining the effect of stereotype content on participants' experiences of schadenfreude and willingness to harm out-group members. We conclude by highlighting implications of our results and future directions for research. Though previous studies have examined group-level schadenfreude, our research is the first to investigate whether stereotypes are sufficient to elicit pleasure in response to the misfortunes of high-status, competitive group members. More important, these are the first experiments to examine whether group-level schadenfreude is related to a tendency to harm those targets 1

\section{Envy and schadenfreude}

Reading the paper, watching the news, walking down the street, gossiping with friends - our lives are replete with opportunities to hear about or witness others' misfortunes. How people respond to others' pain, however, depends on their preexisting prejudices toward the target of the misfortune. Pity or empathy are common responses, but hardly universal Cikara, Bruneau \& Saxe, 2011). An alternative response, schadenfreude refers to the perceiver's experience of pleasure at another's misfortune (Heider, 1958). Several conditions commonly predict schadenfreude (Smith, Powell, Combs \& Schurtz, 2009): (1) when the misfortune benefits the observers (Smith, Eyre, Powell \& Kim, 2006); (2) when the misfortune seems deserved (Feather, 1999; 2006; Feather \& Nairn, 2005' van Dijk, Ouwerkerk, Goslinga \& Nieweg, 2005); and (3) when the misfortune befalls an envied $\operatorname{target}^{2}$ (Brigham, Kelso, Jackson \& Smith, 1997; Smith, Turner, Garonzik, et al., 1996; Takahashi, Kato, Matsuura, et al., 2009). Our work focuses on this last condition because it is the most malicious: the observer does not benefit in any tangible sense, and the misfortune does not serve greater

\footnotetext{
${ }^{1}$ All four studies reported here are published in peer-reviewed journals; citations appear in the references. All findings are significant unless we note otherwise. This article is based on a chapter the authors have written for an edited volume, Schadenfreude (Eds. W. van Dijk \& J. Ouwerkerk).

${ }^{2}$ Several other factors are linked to schadenfreude: anger and hate toward the target (Hareli \& Weiner, 2002), resentment (Feather \& Nairn, 2005; Cuddy, Fiske \& Glick, 2007; Feather \& Sherman, 2002), and self-evaluation threat (van Dijk, Ouwerkerk, Wesseling \& van Koningsbruggen, 2011).
} 
social justice. Instead, envied targets' misfortunes are pleasurable because they make people feel better about themselves (Smith, 2013).

Envy is an inherently social emotion because it is based in social comparison processes; it occurs when people perceive someone else's relative advantage (Parrott \& Smith, 1993; Smith, 2000; Smith \& Kim, 2007). Recent advances in social cognition demonstrate that people feel envious prejudice toward groups just as readily as they envy individual targets (Fiske, Cuddy \& Glick, 2007; Fiske, Cuddy, Glick \& Xu, 2002). Specifically, a successful out-group can make salient one's own group's relative inferiority, generating hostile, groupbased envy ${ }^{3}$ (Smith, 1991). When the out-group or one of its members suffers a misfortune, this sense of inferiority - and we argue, resulting envious prejudice - leads to inter-group schadenfreude (Leach \& Spears, 2008; 2009). Previous studies examining intergroup schadenfreude have employed well-defined, labeled, overtly competitive groups (i.e., rival universities, political parties, soccer teams) (Combs, Powell, Schurtz \& Smith, 2009). Our research investigates whether mere stereotype content is sufficient to elicit schadenfreude. In other words, can groups, by merit of the stereotypes associated with them, and not by anything they have done, evoke malicious joy at their misfortunes?

\section{Which groups are envied? Predictions from the stereotype content model}

People generally prefer their own in-group to out-groups (Tajfel \& Turner, 1979), but not all out-groups are equivalent. The stereotype content model (SCM) (Fiske, Cuddy \& Glick, 2007; Fiske, Cuddy, Glick \& Xu, 2002; Cuddy, Fiske \& Glick, 2007) organizes beliefs about social and cultural groups along two fundamental dimensions of social cognition: warmth and competence. Attributions of warmth are determined by whether the social group is seen as cooperative or competitive (i.e., "are they with us or against us?"). Attributions of competence are guided by whether the social group is high- or low-status (i.e., "are they capable of enacting their intentions?"). In a survey sampling participants across 19 nations, ratings of groups' competitiveness are highly negatively correlated with judgments of group warmth (i.e., $r=-0.52$ ), and status ratings are highly correlated with judgments of group competence (i.e., $r=0.94) .24$ Mapping warmth by competence yields four broad stereotype categories and predicts corresponding prejudices (Fig. 1): groups that seem both warm and competent (e.g., middle class) elicit pride, whereas groups that seem neither warm nor competent (e.g., drug addicts) elicit disgust. The remaining groups elicit ambivalent emotions: stereotypically incompetent but warm groups (e.g., elderly) elicit pity, whereas stereotypically competent but cold groups (e.g., rich people, businesswomen) elicit envy.

Because social comparisons are virtually automatic (Wedell, 1994), simply encountering a high-status target may make an individual's own inferiority salient. Furthermore, high-status targets, if they are also competitive, are more likely to elicit contrastive emotions such as envy (as opposed to assimilative emotions like admiration) (Fiske, Cuddy \& Glick, 2007). Thus, our first prediction: groups that are stereotypically high-status and competitive spontaneously generate envious prejudice: negative affect resulting from an upward,

\footnotetext{
${ }^{3}$ Recent research has revealed that envy can be further broken down into benign and hostile components, which facilitate a desire to improve oneself and tear another person down, respectively (Van de Ven, Zeelenberg \& Pieters, 2009). Our analyses focus on the hostile components of envy.
} 
contrastive social comparison ((Fiske, Cuddy \& Glick, 2007; Fiske, Cuddy, Glick \& Xu, 2002). Given that hostile envy is a potent predictor of schadenfreude, our second prediction is that envied groups are more likely than others to become targets of schadenfreude when they suffer a misfortune. Feeling pleasure instead of empathy disrupts the link between observing others' suffering and being motivated to help them; our third prediction is that targets of schadenfreude are also more subject to harm.

One important social implication of these predictions is that observers can experience schadenfreude in the absence of any interaction (e.g., without history of conflict, explicit competition) with the envied group: sheer knowledge of a group's stereotype will be sufficient. Again, this is critical because these emotions may facilitate tolerance or commission of harm. A complementary theoretical implication is that our approach focusing on social structural variables, that is, status and competition - enables us to generalize our predictions and results to a wide variety of social groups and contexts.

\section{Stereotypes and schadenfreude: empirical evidence}

In our first experiment, we paired photographs of individuals (e.g., a drug addict, an elderly woman, a man in a business suit) with everyday positive, negative, and neutral events (Cikara \& Fiske, 2012). The photographs represented a variety of targets from the four quadrants of the SCM; these pictures had been previously validated as evoking stereotypic traits and emotional responses predicted by the SCM ((Harris \& Fiske, 2006). The events were statements such as "Won a $\$ 5$ bet," "Got soaked by a taxi," and "Went to the bathroom." We did not provide participants with target labels, and we made sure the events were good and bad fortunes that were equally likely to befall all of the targets. Note that none of the events described the target doing something good or bad for which the target was rewarded or punished; this ensured that deservingness could not factor into participants' judgments. We hypothesized that participants would feel congruent affect (e.g., good about positive events) for targets associated with the pride, pity, and disgust quadrants, but incongruent affect (e.g., good about negative events, schadenfreude) for targets associated with the envy quadrant. The existing literature suggested, however, that participants rarely self-report feeling schadenfreude in excess of the midpoint of a scale (van Dijk, Ouwerkerk, Goslinga \& Nieweg, 2005; Takahashi, Matsuura, et al., 2009; Leach \& Spears, 2008; 2009; Leach, Spears, Branscombe \& Doosje, 2003) suggesting the possibility that their responses are distorted by social desirability. To circumvent this challenge, we simultaneously recorded participants' facial muscle movements using facial electromyography (EMG). We predicted that participants would exhibit more positive affect (i.e., smiling), and not just reduced negative affect, in response to envied targets' misfortunes. The implicit measures of positive affect focused on the ZM (zygomaticus major; a cheek muscle) because it correlates reliably with positive affect (Brown \& Schwartz, 1980).

After each trial we asked participants, "If you saw this happening in real life, how good would it make you feel?" and "how bad would it make you feel?" We asked participants these questions separately to allow for ambivalent responding (e.g., they could say they feel simultaneously somewhat bad and somewhat good). As we hypothesized, participants reported that they felt the least congruent affect (i.e., least bad about negative events, and 
least good about positive events) for envy targets as compared to disgust, pity, and pride targets. Participants did not, however, report feeling fully incongruent affect (e.g., significantly better in response to negative events) for envy targets as compared to the other targets. Participants also rated the warmth and competence of all the targets at the end of the study; ratings confirmed the SCM's predictions: participants rated pride and pity targets as significantly warmer than envy and disgust targets, and rated pride and envy targets as significantly more competent than pity and disgust targets.

The facial EMG measures supported all of our hypotheses. Participants smiled more in response to negative than to positive events (an incongruent, schadenfreude response) when they were paired with envy targets, demonstrating the presence of positive affect (not just the absence of negative affect) in response to envied targets' misfortunes. In contrast, participants smiled more in response to positive than to negative events (a congruent response) when they were paired with pride, pity, and disgust targets. We speculated that social desirability increased self-report measurement error, decreasing the response scale's validity and the likelihood that it would co-vary with the physiological measures. These findings also foreshadow a subsequent study: removing social desirability constraints should restore the correlation between self-report and physiological assessments of schadenfreude.

We replicated the self-report findings and assessed participants' willingness to harm targets in a separate experiment. Although it also involved functional magnetic resonance imaging (fMRI), for efficiency we focus on the behavioral findings here (Cikara \& Fiske, 2011). While they were in the scanner, participants viewed the same stimuli from study 1 ; afterward they viewed target-event pairs again and reported on a bipolar scale how they felt in response $(1=$ extremely bad to $9=$ extremely good 0 . Similar to the results of the previous study, participants reported feeling worst about positive events and best about negative events when they were paired with envy targets as compared to all other targets from the SCM. Participants also replicated the target warmth and competence rating findings of experiment 1 . One to two weeks later, we contacted participants with a follow-up websurvey, which presented the following scenario:

You are participating in a Fear Factor type game show and have just won a challenge. This exempts you from the 'punishment' the rest of the players face: they are all going to receive mild electric shocks, which are painful, but not lethal. The game show host gives YOU the choice to decide whether all five of the players are going to get shocks or if one person should get a stronger shock (which is again, painful, but not lethal) while you spare the other four.

We asked participants how willing they would be to volunteer each target they saw during the scan to receive a shock so that the other, undifferentiated players could avoid the punishment $(1=$ not at all, $7=$ extremely $)$. Participants provided a rating for each SCM 
target ${ }^{4}$. In support of our hypothesis, participants were more likely to subject an envy target to harm as compared to pity, disgust, and pride targets ${ }^{5}$.

Thus far we had demonstrated that stereotypes reflecting high-status competence and lowwarmth competitiveness are sufficient to predict schadenfreude. By this logic, increasing an envied group's perceived cooperation or decreasing its status should reduce schadenfreude. In a third experiment, we manipulated group status and competition by providing participants with counter-stereotypic information about a specific social group from the envied quadrant: investment bankers (Cikara \& Fiske, 2012). Participants read a newspaper article about one of several investment bankers: whose situations were status quo (envy); who were advising small businesses, pro bono, to help the economy as a whole (decreases competitiveness: pride); who were using the last of their bonuses to fund their drug habits (decreases status: disgust); or who were unemployed but still dressing up in their suits and pretending to go to work (decreases both status and competitiveness: pity). We predicted that participants would report significantly worse feelings about envied targets' experience of negative events, after participants had been primed by the pride, disgust, and pity vignettes, as compared to the envy vignette. The vignettes focused on one group within the envy quadrant, so we further predicted that the effects of the vignette would be specific to targets resembling investment bankers. A manipulation check at the end of the study confirmed that participants rated the characters in the newspaper articles as the SCM predicts: significantly less warm in the disgust and envy manipulations than in the pity and pride manipulations; significantly less competent in the disgust and pity manipulations as compared to the envy and pride manipulations. In support of our hypothesis, counterstereotypic status and competition information about an investment banker increased how bad participants said they felt about negative events happening to novel envy targets, but only those who resembled investment bankers. Thus, this study establishes that stereotype content, and not specific relationships to individual targets themselves, predicts schadenfreude.

Our final experiment probed the relationships among envy, schadenfreude, and harm in the context of a real-world conflict: Red Sox versus Yankees fans, historic rivals in American baseball (Cikara, Botvinick \& Fiske, 2011). Remember that participants' self-reported affect was not related to their ZM responses (i.e., smiling) in study 1 . We speculated that social desirability decreased participants' willingness to report feeling schadenfreude, which suggests that physiological indicators of schadenfreude should correlate with self-reported affect when social desirability concerns are absent. Sports, politics, and celebrity gossip are a few domains in which it is acceptable, even desirable, to express pleasure at others' misfortunes (Smith, Powell, Combs \& Schurtz, 2009; Combs, Powell, Schurtz \& Smith, 2009), so we predicted that the physiological/self-report correlation would be restored. And even though participants had more than stereotype content in the context of this study, we

\footnotetext{
${ }^{4}$ We posed the harm question in the context of a trade-off to loosen demand characteristics (Cikara, Farnsworth, Harris \& Fiske, 2010). Participants' responses theoretically represent their willingness to spare the other contestants as well as their willingness to harm the target, but because we held the contestants to be spared constant, response variation reflects only differences in willingness to harm different targets. The gameshow scenario also limits the information available for participants' consideration to stereotypes associated with the targets.

${ }^{5}$ This last comparison was only significant with a one-tailed test.
} 
predicted that warmth and competence ratings, as well as feelings of envy, would conform to predictions from the SCM. Pre-experiment survey data confirmed that all fans rated their favored team as most warm and competent, the Orioles (a relatively less competitive team in the same league) as moderately warm and moderately competent, and most importantly, their rival as more competent than the Orioles, but also less warm. Participants also said they envied their rivals more than the Orioles.

We collected functional magnetic resonance imaging (fMRI) data while Red Sox and Yankees fans who were prescreened for intense fandom, viewed baseball plays involving their favored team, rival team, and two other teams succeeding and failing to get on base; participants also rated how much pleasure, pain, and anger each play made them feel. As predicted, participants reported experiencing more pleasure during subjectively positive outcomes - when their favored team scored against their rival, their rival failed to score against their favored team, and critically, their rival failed to score against the Orioles, a relatively less competitive third team (pure schadenfreude condition) - as compared to plays in the control condition (the Orioles failing and succeeding against a fourth team, the Blue Jays). In addition, participants reported experiencing more pain and anger during subjectively negative outcomes (when their favored team failed to score against their rival and when their rival scored against their favored team) as compared to the control condition. We assessed willingness to harm rivals in a follow-up web survey, administered approximately two weeks after the participant's scan. Both Red Sox and Yankees fans reported that they were more likely to heckle, insult, threaten, and hit a rival fan as compared to an Oriole's fan.

Our fMRI analyses examined whether participants' self-reported pleasure and pain were reflected in the responses of neural structures associated with representing primary rewards and punishments. Previous research has shown that the ventral striatum (VS) is engaged not only when participants experience primary (e.g., food) and more abstract forms of reward (e.g., money) (Berns, McClure, Pagnoni \& Montague, 2001; O'Doherty, 2004), but also when they receive relatively greater rewards than someone else (Fliessbach, Weber, Trautner, et al., 2007). In parallel, the anterior cingulate cortex (ACC) and the anterior insula are engaged not only when people experience pain themselves, but also when they observe others in pain (Botvinick, Jha, Bylsma, et al., 2005; Decety \& Ickes, 2009). Several more recent studies, however, demonstrate that participants exhibit the opposite pattern of neural responses when rewards and punishments are doled out to competitors (Takahashi, Kato, Matsuura, et al., 2009; de Bruijn, de Lange, von Cramon \& Ullsperger, 2009; Singer, Seymour, O'Doherty, et al., 2006).

In line with our predictions, Red Sox and Yankees fans exhibited greater VS responses while watching their rival team fail and their favored team score, relative to the control condition; as predicted, participants' VS responses were also correlated with their subjective reports of pleasure. Fans also exhibited greater ACC and insula responses while watching their favored team fail and their rival team score; again, as predicted, ACC responses correlated with subjective reports of pain. Most important, VS responses while viewing competitive rival failures (even against the Orioles) were correlated with self-reported likelihood of harming rival team fans. 


\section{Discussion}

We have reviewed our program of research demonstrating that mere stereotype content regarding the status and competitiveness of targets predicts which stereotyped groups are targets of empathy and which are targets of schadenfreude and harm. While participants do not always report overt schadenfreude, their physiological responses reflect the presence of pleasure (and not just the absence of pain) in response to envied targets' misfortunes. In contexts where confessing to schadenfreude is socially acceptable, self-reported affect tracks physiological indicators of pleasure. More importantly, this pleasure is associated with willingness to harm envied out-group members. Though stereotype content is sufficient to elicit these malevolent emotional responses, these effects are malleable: manipulating perceptions of status and competition can reduce and eliminate schadenfreude toward stereotypically envied targets.

\section{Implications}

This suite of studies clearly demonstrates the importance of using a variety of methods to assess the relationships among stereotype content, schadenfreude, and harm. Because overtly expressing schadenfreude is socially undesirable in most contexts, people may feel uncomfortable or unable to respond naturally in experimental settings. These dynamics have made studying schadenfreude a methodological challenge. Using indirect measures such as fMRI and facial EMG to complement explicit self-report helps to circumvent some of the hurdles associated with measuring socially undesirable emotions and behaviors.

Broader social and ethical implications of this work suggest that schadenfreude may play a central role in the escalation of intergroup conflict, particularly under competition for zerosum resources between two groups (e.g., territory for Israel and Palestine). In any hierarchical social system, status discrepancies are recognized, enacted, and maintained by its respective constituents. This suggests that individual group members need not have a personal history of conflict in order to feel motivated to harm one another, particularly if group relations are already hostile. If it feels pleasurable to actively harm or passively observe the harm of an envied group, this harmful behavior may be much more likely to persist and possibly escalate over time. Intergroup emotions also play a powerful role in the elicitation and maintenance of discrimination among groups who are not in direct conflict. In the United States, stereotypes regarding status and competitiveness breed dislike for "model minorities" (e.g., Jews, Asians) and successful subordinate group members (e.g., black professionals, career women). A more refined understanding of the processes underlying stereotyping and the resulting emotional and behavioral consequences might help inform ethical policies that effectively mitigate social inequality.

Envy and schadenfreude may also have serious implications for a number of other areas of psychological inquiry including but not limited to: negotiation (particularly between parties of disparate means or status) (Zizzo \& Oswald, 2001), health and well-being (e.g., life satisfaction is better predicted by relative income as opposed to absolute income) (Diener, Sandvik, Seidlitz \& Diener, 1993), even consumption and economic growth (e.g., people's use of the accumulation of material goods as comparative benchmarks of success). This 
research will be useful in furthering our understanding of psychological processes related to the effects of inequality between people and groups more generally. Most important, these findings may help us reduce the threatening nature of envy, as hostile reactions are more extreme if they are caused by emotions that threaten one's identity or group.

\section{Future directions}

Future work should interrogate the possible functions of group-level schadenfreude. It is not a coincidence that genocide and mass violence have often targeted ethnic groups that appear in the envy quadrant of the SCM (Staub, 1989). Consider the Jews in Europe, the Chinese in Indonesia, and the Tutsi in Rwanda: all elite minorities in their respective contexts.

Schadenfreude may function as a signal of in-group cohesion, in opposition to threatening competitors. Demonstrating pleasure instead of empathy in response to someone's misfortune is a clear sign to both in-group and out-group members that one's interests are not aligned with the victim's (Weisbuch \& Ambady, 2008). If resentment toward an outgroup is publically sanctioned, it may reinforce the perception that the other group's advantage merits a hostile response.

People may also be actively motivated to experience the positive emotions and selfaffirmation afforded by schadenfreude (van Dijk, Ouwerkerk, Wesseling \& van Koningsbruggen, 2011). When an out-group is perceived as antagonistic, people feel less empathy for out-group members, but also more empathy for in-group members (Dovido, Johnson, Gaertner, et al., 2010). Because of the negative implications of envy for the self, groups may cope with envy by finding ways to justify their ill will (e.g., promoting in-group pride, construing the envied group's success as undeserved or unfairly attained).

\section{Conclusion}

People often fail to empathize and may even feel pleasure in response to out-group targets' misfortunes. However, not all out-groups are equivalent: high-status, competitive groups are more likely to be targets of schadenfreude than other out-groups. More important, they are also more likely to be targets of harm. Knowing that perceptions of status and competitiveness drive these responses allows us to predict which groups are at greatest risk in times of social instability. Furthermore, knowing that these perceptions are malleable makes it possible to ameliorate pernicious affective and behavioral responses when outgroups are targets of misfortune or overt harm. Elucidating the boundary conditions of empathy and predictors of counter empathic responding is essential for predicting people's behavior across a variety of ethically consequential contexts including, but not limited to, policy preferences, discrimination within societies, and intergroup conflict.

\section{Acknowledgments}

The authors gratefully acknowledge financial support from the following for the research, authorship, and publication of this paper: the Russell Sage Foundation, the Princeton Neuroscience Institute, Princeton University's Center for Human Values, Joint Degree Program in Social Policy, and the Charlotte Elizabeth Procter Fellowship, awarded by Princeton University to MC. 


\section{References}

Batson, CD. These things called empathy: eight related but distinct phenomena. In: Decety, J.; Ickes, WJ., editors. The Social Neuroscience of Empathy. Cambridge, MA: MIT Press; 2009. p. 3-15.

Batson CD, Ahmad NY. Using empathy to improve intergroup attitudes and relations. Soc Issues Pol Rev. 2009; 3:141.

Berns GS, McClure SM, Pagnoni G, Montague PR. Predictability modulates human brain response to reward. J Neurosci. 2001; 21:2793-2798. [PubMed: 11306631]

Botvinick M, Jha AP, Bylsma LM, et al. Viewing facial expressions of pain engages cortical areas involved in the direct experience of pain. NeuroImage. 2005; 25:312-319. [PubMed: 15734365]

Brigham NL, Kelso KA, Jackson MA, Smith RH. The roles of invidious comparisons and deservingness in sympathy and schadenfreude. Basic Appl Soc Psychol. 1997; 19:363-380.

Brown S, Schwartz GE. Relationships between facial electromyography and subjective experience during affective imagery. Biol Psychol. 1980; 11:49-62. [PubMed: 7248403]

Cikara M, Fiske ST. Stereotypes and schadenfreude: behavioral and physiological markers of pleasure at others' misfortunes. Soc Psychol Pers Sci. 2012; 3:63-71.

Cikara M, Farnsworth RA, Harris LT, Fiske ST. On the wrong side of the trolley track: neural correlates of relative social valuation. Soc Cogn Affect Neurosci. 2010; 5:404-413. [PubMed: 20150342]

Cikara M, Botvinick MM, Fiske ST. Us versus them: social identity shapes neural responses to intergroup competition and harm. Psychol Sci. 2011; 22:306-313. [PubMed: 21270447]

Cikara M, Bruneau EG, Saxe R. Us and them: intergroup failures of empathy. Curr Direct Psychol Sci. $2011 ; 20: 149-153$.

Cikara M, Fiske ST. Bounded empathy: neural responses to out-group targets' (mis)fortunes. J Cogn Neurosci. 2011; 23:3791-3803. [PubMed: 21671744]

Combs DJY, Powell CAJ, Schurtz DR, Smith RH. Politics, Schadenfreude, and ingroup identification: the sometimes happy thing about a poor economy and death. Exp Soc Psychol. 2009; 45:635-646.

Cosmides L, Tooby J, Kurzban R. Perceptions of race. Trends Cogn Sci. 2003; 7:173-179. [PubMed: 12691766]

Cuddy AJC, Fiske ST, Glick P. The BIAS map: behaviors from intergroup affect and stereotypes. J Pers Soc Psychol. 2007; 92:631-648. [PubMed: 17469949]

Davis, MH. Empathy: A Social Psychological Approach. Boulder, CO: Westview Press; 1994.

de Bruijn ER, de Lange FP, von Cramon DY, Ullsperger M. When errors are rewarding. J Neurosci. 2009; 29:12183-12186. [PubMed: 19793976]

Decety, J.; Ickes, WJ. The Social Neuroscience of Empathy. Cambridge, MA: MIT Press; 2009.

Diener E, Sandvik E, Seidlitz L, Diener M. The relationship between income and subjective wellbeing: relative or absolute? Soc Indicat Res. 1993; 28:195-223.

Dovidio, JF.; Johnson, JD.; Gaertner, SL., et al. Prosocial Motives, Emotions, and Behavior: The Better Angels of Our Nature. Washington, DC: American Psychological Association; 2010. Empathy and intergroup relations; p. 393-408.

Feather, NT. Values, Achievement, and Justice: Studies in the Psychology of Deservingness. New York, NY: Kluwer Academic/Plenum Press; 1999.

Feather NT. Deservingness and emotions: applying the structural model of deservingness to the analysis of affective reactions to outcomes. Eur Rev Soc Psychol. 2006; 17:38-73.

Feather NT, Sherman R. Envy, resentment, schadenfreude, and sympathy: reactions to deserved and underserved achievement and subsequent failure. Pers Soc Psychol Bull. 2002; 28:953-961.

Feather NT, Nairn K. Resentment, envy, schadenfreude, and sympathy: effects of own and other's deserved or undeserved status. Aust J Psychol. 2005; 57:87-102.

Fiske ST, Cuddy AJC, Glick P. Universal dimensions of social cognition: warmth and competence. Trends Cogn Sci. 2007; 11:77-83. [PubMed: 17188552]

Fiske ST, Cuddy AJC, Glick P, Xu J. A model of (often mixed) stereotype content: competence and warmth respectively follow from perceived status and competition. Pers Soc Psychol. 2002; 82:878-902. 
Fliessbach K, Weber B, Trautner P, et al. Social comparison affects reward-related brain activity in the human ventral striatum. Science. 2007; 318:1305-1308. [PubMed: 18033886]

Hareli S, Weiner B. Dislike and envy as antecedents of pleasure at another's misfortune. Motiv Emot. 2002; 26:257-277.

Harris LT, Fiske ST. Dehumanizing the lowest of the low neuroimaging responses to extreme outgroups. Psychol Sci. 2006; 17:847-853. [PubMed: 17100784]

Heider, F. The Psychology of Interpersonal Relations. New York: Wiley; 1958.

Hornstein, HA. Promotive tension and prosocal behavior: a Lewinian analysis. In: Wispe, L., editor. Altruism, Sympathy, and Helping: Psychological and Sociological Principles. New York: Academic; 1978. p. 177-207.

Johnson J, Simmons C, Jordan A, et al. Rodney King and O. J. revisited: the impact of race and defendant empathy induction on judicial decisions. J Appl Soc Psychol. 2002; 32:1208-1223.

Keltner, D. Born to be Good: The Science of a Meaningful Life. New York: W. W. Norton\& Company; 2009.

Leach CW, Spears R. "A vengefulness of the impotent": the pain of ingroup inferiority and schadenfreude toward successful outgroups. J Pers Soc Psychol. 2008; 95:1383-1396. [PubMed: 19025290]

Leach CW, Spears R. Dejection at in-group defeat and schadenfreude toward second- and third-party out- groups. Emotion. 2009; 9:659-665. [PubMed: 19803588]

Leach CW, Spears R, Branscombe NR, Doosje B. Malicious pleasure: schadenfreude at the suffering of another group. J Pers Soc Psychol. 2003; 84:923-943.

O'Doherty JP. Reward representations and reward-related learning in the human brain: insights from neuroimaging. Curr Opin Neurobiol. 2004; 14:769-776. [PubMed: 15582382]

Parrott WG, Smith RH. Distinguishing the experiences of envy and jealousy. J Pers Soc Psychol. 1993; 64:906-920. [PubMed: 8326472]

Singer T, Seymour B, O'Doherty JP, et al. Empathic neural responses are modulated by the perceived fairness of others. Nature. 2006; 439:466-469. [PubMed: 16421576]

Smith, RH. Envy and the sense of injustice. In: Salovey, P., editor. The Psychology of Jealousy and Envy. New York, NY: Guilford Press; 1991. p. 79-99.

Smith, RH. Assimilative and contrastive emotional reactions to upward and downward social comparisons. In: Suls, J.; Wheeler, L., editors. Handbook of Social Comparison: Theory and Research. Dordrecht, the Netherlands: Kluwer; 2000. p. 173-200.

Smith, RH. The Joy of Pain: Schaudenfreude and the Dark Side of Human Nature. Oxford: Oxford University Press; 2013.

Smith RH, Eyre HL, Powell CA, Kim SH. Relativistic origins of emotional reactions to events happening to others and to ourselves. Br J Soc Psychol. 2006; 45:357-371. [PubMed: 16869064]

Smith RH, Kim SH. Comprehending envy. Psychol Bull. 2007; 133:46-64. [PubMed: 17201570]

Smith RH, Powell CAJ, Combs DJY, Schurtz RD. Exploring the when and why of schadenfreude. Soc Pers Psychol Compass. 2009; 3:530-546.

Smith RH, Turner TJ, Garonzik R, et al. Envy and schadenfreude. Pers Soc Psychol Bull. 1996; 22:158-168.

Staub, E. The Roots of Evil: The Origins of Genocide and Other Group Violence. New York: Cambridge; 1989.

Tajfel, H.; Turner, J. An integrative theory of intergroup conflict. In: Austin, WG.; Worschel, S., editors. The Social Psychology of Intergroup Relations. Pacific Grove, CA: Brooks/Cole Publishing; 1979. p. 33-47.

Takahashi H, Kato M, Matsuura M, et al. When your gain is my pain and your pain is my gain: neural correlates of envy and Schadenfreude. Science. 2009; 323:937-939. [PubMed: 19213918]

Tomasello, M. Why We Cooperate. Cambridge, MA: MIT Press; 2009.

Van de Ven N, Zeelenberg M, Pieters R. Leveling up and down: the experiences of benign and malicious envy. Emotion. 2009; 9:419-429. [PubMed: 19485619]

van Dijk WW, Ouwerkerk JW, Goslinga S, Nieweg M. Deservingness and schadenfreude. Cogn Emot. 2005; 19:933-939. 
van Dijk WW, Ouwerkerk J, Wesseling YM, van Koningsbruggen GM. Towards understanding pleasure at the misfortunes of others: the impact of self-evaluation threat on schadenfreude. Cogn Emot. 2011; 25:360-368. [PubMed: 21432678]

Wedell DH. Contextual contrast in evaluative judgments: a test of pre- versus postintegration models of contrast. J Pers Soc Psychol. 1994; 66:1007-1019.

Weisbuch M, Ambady N. Affective divergence: automatic responses to others' emotions depend on group membership. J Pers Soc Psychol. 2008; 95:1063-1079. [PubMed: 18954194]

Zizzo DJ, Oswald AJ. Are people willing to pay to reduce others incomes? Ann Econ Statist. 2001; 63-64:39-62. 


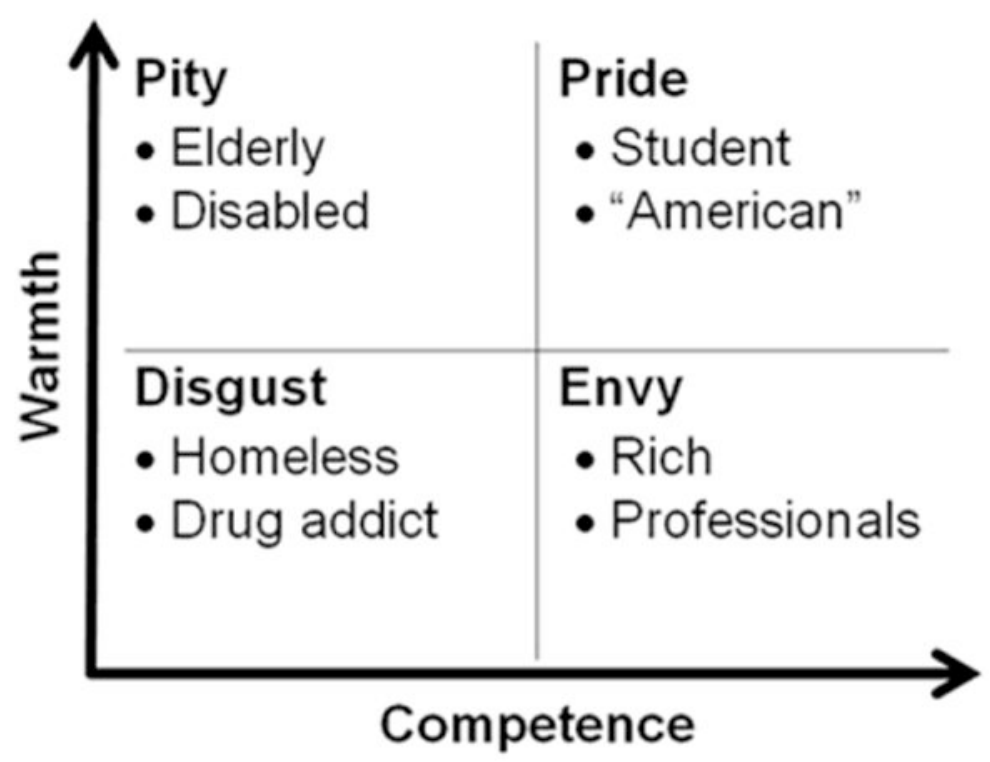

Figure 1.

The stereotype content model: warmth by competence space, stereotyped group exemplars, and associated emotions. Perceived competition predicts stereotypic low warmth, and perceived status predicts stereotypic competence. Source data from Ref. 35, figure from Ref. 55. 